Etnográfica

Revista do Centro em Rede de Investigação em

Antropologia

vol. $23(2) \mid 2019$

Vol. $23(2)$

\title{
Metáforas térmicas: turistas europeus no Nordeste brasileiro narrando a intimidade
}

Thermic metaphors: European tourists in Northeastern Brazil narrating intimacy

\section{Octávio Sacramento}

\section{(2) OpenEdition}

\section{Journals}

Edição electrónica

URL: https://journals.openedition.org/etnografica/6762

DOI: 10.4000/etnografica.6762

ISSN: 2182-2891

\section{Editora}

Centro em Rede de Investigação em Antropologia

\section{Edição impressa}

Data de publição: 1 junho 2019

Paginação: 335-357

ISSN: 0873-6561

\section{Refêrencia eletrónica}

Octávio Sacramento, «Metáforas térmicas: turistas europeus no Nordeste brasileiro narrando a intimidade», Etnográfica [Online], vol. 23 (2) | 2019, posto online no dia 24 junho 2019, consultado o 20 janeiro 2022. URL: http://journals.openedition.org/etnografica/6762 ; DOI: https://doi.org/10.4000/ etnografica.6762

\section{(c) (7) (8)}

Etnográfica is licensed under a Creative Commons Attribution-NonCommercial 4.0 International License. 


\section{Metáforas térmicas: turistas europeus no Nordeste brasileiro narrando a intimidade}

\section{Octávio Sacramento}

Fomentado por uma etnografia das configurações de intimidade euro-brasileiras associadas ao turismo no bairro de Ponta Negra (Natal-RN, Nordeste do Brasil), o artigo centra-se nas representações, expectativas e experiências de turistas europeus envolvidos em relações passionais transatlânticas. Os discursos e as práticas destes turistas evidenciam desejos de construir alternativas às formas de convivência íntima na Europa e de encontrar circunstâncias favoráveis à (re)afirmação de identidades masculinas que, alegadamente, a emancipação feminina e o peso das obrigações quotidianas terão entorpecido. Na sua discursividade sobressaem metáforas térmicas de perfil binário nas quais o Brasil é simbolizado como triplamente "quente" (clima, sociabilidades e sexualidade), sempre em relação e por oposição à "fria" Europa. Enquanto elementos de indexação simbólica, estas metáforas permitem aceder à compreensão das subjetividades, expressões identitárias e vivências de intimidade masculinas nos trópicos e, simultaneamente, a alguns dos desígnios que fundam as mobilidades turísticas em causa.

PALAVRAS-CHAVE: turismo, intimidades euro-brasileiras, metáforas térmicas, masculinidade.

Thermic metaphors: European tourists in Northeastern Brazil narrating intimacy - Propelled by an ethnography of Euro-Brazilian intimacy configurations associated with tourism in the Ponta Negra district (Natal-RN, Northeastern Brazil), the article focuses on the representations, expectations and experiences of European tourists involved in transatlantic passionate affairs. The discourses and practices of these tourists show the desire to construct alternatives to the modes of intimate association in Europe and to find favorable circumstances to (re)affirm masculine identities that allegedly feminine emancipation and the burden of everyday obligations would have numbed. In the tourists' discourse, binary thermic metaphors stand out in which Brazil is symbolized as triply "hot" (regarding climate, sociability and sexuality), always with reference and in contrast to the "cold" Europe. As symbolic indexing elements, these metaphors enable access to the understanding of subjectivities, identity expressions and experiences of male intimacy in the tropics, and, at the same time, to some of the purposes underlying these touristic mobilities.

KEYWORDS: tourism, Euro-Brazilian intimacies, thermic metaphors, masculinity.

SACRAMENTO, Octávio (octavsac@utad.pt) - Centro de Estudos Transdisciplinares para o Desenvolvimento, Universidade de Trás-os-Montes e Alto Douro (Cetrad-UTAD); Centro em Rede de Investigação em Antropologia, polo ISCTE-IUL (CRIA-IUL), Portugal. 


\section{INTRODUÇÃO}

As mobilidades turísticas entre a Europa e o Brasil, à semelhança de muitos outros fluxos atlânticos, proporcionam encontros e aproximações passionais que transpõem fronteiras político-administrativas e fronteiras identitárias. No âmbito do meu doutoramento em antropologia (Sacramento 2014), tomei como objeto de estudo estes relacionamentos íntimos transfronteiriços e os trânsitos turísticos e migratórios a eles associados. ${ }^{1}$ Nesse sentido, desenvolvi uma abordagem etnográfica das configurações de intimidade heterossexuais adultas (v.g. eróticossexuais, afetivas, românticas e conjugais) entre homens europeus e mulheres brasileiras que se conheceram durante a estadia turística dos primeiros no bairro de Ponta Negra, proeminente destino balnear de massas na cidade de Natal-RN, no Nordeste do Brasil. Com base nesta pesquisa de terreno, proponho-me debater aqui as representações, expectativas e experiências dos turistas europeus (gringos) envolvidos em relacionamentos transatlânticos, considerando, simultaneamente, alguns dos quadros de normas e valores que regulam as suas manifestações de masculinidade e a organização da sua vida íntima.

Tendo em conta que os vínculos e as vivências passionais constituem espaços sociais tendencialmente reservados e de difícil acesso ao antropólogo - muito em especial "a vida doméstica privada" (Almeida 2004: 176) -, a análise recai sobretudo nas narrativas de intimidade dos europeus que se deslocam a Ponta Negra para uma estadia turística, embora sempre muito apoiada nos elementos empíricos de natureza mais contextual proporcionados pelo trabalho de campo etnográfico. $\mathrm{Na}$ discursividade dos informantes presto especial atenção aos elementos idiomáticos figurativos através dos quais operam metáforas térmicas de perfil binário, polarizadas qualitativamente em torno do "quente" e do "frio", numa relação antitética em que o primeiro tende a ser categorizado como polo positivo e o segundo como polo negativo. Com uma genealogia indissociável das construções identitárias coloniais e pós-coloniais, estas metáforas funcionam como referenciais simbólicos matriciais na projeção de sentidos socioeróticos diferenciados para os dois lados do Atlântico e na tradução das subjetividades, expressões identitárias e experiências de intimidade masculinas nos trópicos por contraponto à Europa da vida de todos os dias. No contexto turístico cubano, Simoni debate esta "oposição relacional” a partir do que designa por estereótipo "caliente", o qual "[...] helps explain the overarching characterization of Cuban people as 'hot', or at least 'hotter' than the foreigners visiting the tropical island" (Simoni 2013: 185). 
A abordagem que procuro desenvolver, sendo eminentemente antropológica, não se circunscreve aos elementos metafóricos como meras unidades de retórica, mas como recursos culturais, tendo presente que "people live by their metaphors, that they think through them and act on them" (Kimmel 2004: 275). Ortega y Gasset referia mesmo que "la metáfora es probablemente la potencia más fértil que el hombre posee. Su eficiencia llega a tocar los confines de la taumaturgia y parece un trebejo [utensílio] de creación que Dios dejó olvidado dentro de una de sus criaturas al tiempo de formarla" (2005 [1917-1925]: 865). Enquanto dispositivos de grande densidade semântica, presentes em estilos de vida, práticas, perceções, pensamentos e identidades de múltiplos contextos sociais da vida quotidiana (Fernandez 1991; Fischer 2012; Lakoff e Johnson 2003 [1980]; Sunderland e Denny 2016; Turner 1974), as metáforas indexam formas de fazer e estar no "mundo" de que fala Pina-Cabral (2017). Afiguram-se, por isso, como portas de entrada para a exploração etnográfica desse "mundo", do modo como os sujeitos nele se dispõem, o apreendem e constituem. No caso aqui em discussão, as metáforas térmicas evidenciam singular abrangência e (omni)potência simbólica, sendo usadas pelos indivíduos com uma ampla flexibilidade significante e com uma grande economia discursiva-reflexiva para traduzir diferentes aspetos, situações e manifestações sociais. Comparo-as, por isso, a uma chave mestra que facilita o acesso do olhar antropológico às noções que pautam, inscrevem sentido e fundam os desígnios de "transnacionalização da intimidade" (King 2002) dos turistas europeus no espaço atlântico.

\section{HOMENS ABAIXO DO EQUADOR PROCURANDO OUTROS CENÁRIOS DE INTIMIDADE}

O turismo é um campo social configurado por "gendered mobilities" (Cresswell e Uteng 2008), no qual se destaca a presença de homens e a manifestação de processos de afirmação de diferentes perfis de masculinidade (Thurnell-Read e Casey 2015). Os fluxos turísticos do continente europeu para Ponta Negra, um pouco à semelhança do que já foi constatado em contextos idênticos (Cabezas 2009; Gomes et al. 2010; Piscitelli 2004a; Simoni 2015), são constituídos sobretudo por homens viajando em grupo. Com idades que tendem a situar-se entre os 25 e os 45 anos, estes homens são provenientes, na sua grande maioria, da região mediterrânica (mormente do Norte de Itália), estão solteiros ou separados/divorciados, têm uma formação académica intermédia e integram os grupos socioprofissionais dos empregados executantes (v.g. funcionários do comércio) e dos operários (Sacramento 2014, 2018). ${ }^{2}$ No quadro da sua

2 Contudo, não é de todo incomum a presença de turistas com idades inferiores e superiores ao intervalo indicado. Como se poderá constatar ao longo do texto, alguns dos meus principais informantes têm idades na ordem dos 50, 60 e 70 anos. 
estadia turística são bastante comuns as relações de intimidade com parceiras brasileiras, geralmente mais jovens (20-30 anos, a maioria). Estas relações ocorrem com mulheres que prestam serviços sexuais remunerados ("garotas de programa”), socialmente mais acessíveis a priori, mas também com muitas outras que, embora não se assumindo ou sendo tidas como tal, se guiam por um conglomerado mais ou menos idêntico de expectativas e de estratégias, identificando o "gringo" europeu como o "homem certo" para a concretização das suas pretensões materiais, românticas e familiares.

A mobilidade turística masculina com destino a Ponta Negra é, em larga medida, indissociável das transformações estruturais na organização da vida íntima e da sua emergência como espaço de reflexividade e individualização, delineado em progresso a partir de referenciais internos (Giddens 2001 [1992]) nos quais convergem elementos de diversos sistemas de significação. Num tempo marcado pela considerável capacidade eletiva individual, desde logo nas questões passionais (Roca Girona 2007, 2011), são muitos os europeus que, insatisfeitos face às identidades e aos relacionamentos de género nos seus países, cruzam o Atlântico movidos por representações (históricas) do Brasil como destino que, entre outras coisas, lhes poderá proporcionar novas e melhores experiências de intimidade. ${ }^{3}$ Através desta mobilidade, tentam encontrar na alteridade aquilo que alegam não encontrar numa escala de proximidade e, desse modo, concretizar no plano transnacional as elevadas expectativas que, atualmente, acompanham as conceções mais comuns sobre o sexo, o romance e a conjugalidade (Beck e Beck-Gernsheim 2004). Transpondo "fronteiras etnossexuais" (Nagel 2003), forjadas no quadro dos impérios transatlânticos (Stolcke 2006), e carregando um denso lastro históricocultural de representações sexualizadas e racializadas do Brasil, sintetizadas na figura icónica da "mulata", esperam descobrir abaixo do Equador outras formas de feminilidade, que os próprios, consoante as circunstâncias e de modo algo ambíguo, qualificam como "menos emancipadas", "tradicionais", "dedicadas ao homem", "naturais" e/ou "quentes". Ao mesmo tempo, visam aceder a cenários de convivência heterossexual mais condizentes com as suas subjetividades e ensaiar outras experiências e sensações de masculinidade.

As interações íntimas de homens ocidentais com mulheres locais em contextos turísticos do Sul global são, amiúde, rotuladas como turismo sexual. Entre muitos outros enviesamentos analíticos que o "conceito" pressupõe, ele tende a uniformizar manifestações empíricas heterogéneas e a sobrevalorizar

3 Tal como referi em texto anterior (Sacramento 2018), as biografias destes turistas indiciam muitas das atuais tendências sociodemográficas dos países europeus - aumento do celibato e do divórcio, casamento tardio, redução da nupcialidade -, associadas às mudanças nos modelos de intimidade e família: mutações nas identidades e relações de género, individualização, turbulência das relações amorosas e novas disposições dos vínculos conjugais e parentais (Beck e Beck-Gernsheim 2004; Giddens 2001 [1992]; Illouz 1999; Roca Girona 2011). 
elementos considerados mais estritamente sexuais (Sacramento 2016a), como se fossem uma marca distintiva da sua singularidade e estivessem, de todo, ausentes de outras modalidades turísticas. Com isto não quero dizer que o sexo é secundário nestas manifestações. Somente procuro ressalvar que se trata de uma dimensão também incontornável noutros "tipos" de turismo - mesmo no turismo cultural que remonta ao grand tour (Littlewood 2001) ${ }^{4}$ e que, como nos mostram os elementos etnográficos mais adiante, coexiste de modo variável, circunstancial e até paradoxal, em permanente negociação, com outros "idiomas relacionais" (Simoni 2015), como é o caso do amor romântico (Hoefinger 2013; Kummels 2005; Piscitelli 2016). Esta coexistência pode, inclusivamente, verificar-se no âmbito específico da mercantilização da sexualidade, esbatendo demarcações entre o "programa", o "ficar" ou o namoro. Mesmo aqui, sexo e emoção (e dinheiro) não são, necessariamente, polos antinómicos (Williams 2013), ainda que, por vezes, como veremos, os atores sociais assim os entendam. Importa ter sempre presente que "Sex + tourism is not what it seems at face value, and the job of anthropology, as always, is to delve deeply past the smoke and mirrors" (Frohlick 2010: 67).

Ainda que o sexo constitua uma dimensão proeminente nas expectativas da generalidade dos europeus que afluem a Ponta Negra, é manifestamente simplista assumir-se que a sua deslocação ao Brasil é movida apenas por desígnios eróticossexuais. Ainda mais redutora se afigura a ideia de Brennan (2004: 314) para o contexto dominicano, segundo a qual uma das demandas destes homens seria "[...] buy sex for cheaper prices than in their home countries". Se assim fosse, porquê atravessar o Atlântico, quando nos seus países o mercado do sexo acolhe grandes fluxos migratórios femininos provenientes da América do Sul, nomeadamente do Brasil (Piscitelli 2009, 201 1; Ribeiro et al. 2007), e lhes disponibiliza experiências de sexualidade diversificadas e a preços não tão elevados como Brennan (2004) dá a entender? Aliás, uma parte muito considerável dos turistas que conheci teve os primeiros relacionamentos com mulheres brasileiras no âmbito da prostituição (na Europa) e o principal foco de descontentamento face a elas não está relacionado com preços, mas sim com o alegado carácter impessoal e "profissional" da relação: "Aqui [Brasil], elas beijam na boca, envolvem-se e tiram prazer. Na Europa... e eu sei, porque já tive relações com muitas prostitutas, é muito diferente. Elas abrem as pernas e só estão a olhar para o relógio" [turista italiano, 30 anos]. Porém, segundo alguns turistas que já frequentam o contexto desde finais da década de 1990, em Ponta Negra as relações de intimidade têm vindo a tornar-se mais mercantilizadas e as "garotas de programa" mais "profissionais".

4 Depois de analisar documentos relativos aos aspetos mais íntimos das viagens culturais de Lord Byron, de Oscar Wilde e de outros escritores, Littlewood (2001) mostra-nos que as suas digressões turísticas, a par da erudição, tinham subjacente uma forte componente sexual. 
Mesmo com uma considerável e diversificada oferta de serviços sexuais nos seus países, há qualquer coisa, para lá daquilo que consideram ser a esfera da sexualidade, a que anseiam ter acesso durante a estadia turística. O que a etnografia em Ponta Negra mostra é que, de um modo geral, os turistas europeus procuram configurações de intimidade relativamente abrangentes, combinando numa geometria variável sexo, romance e mesmo a possibilidade de delinear projetos conjugais (Sacramento 2016b). Mais restringida ou menos restringida aos circuitos sociais dos "programas", conforme o conhecimento do contexto e a rede de contactos locais, esta procura é impulsionada pelo desígnio, muitas vezes gorado, de alcançar interações passionais o mais próximas possível daquilo que julgam ser a norma configuracional das relações íntimas; onde, desde logo, não esteja presente o ato explícito do pagamento que tende a caracterizar a prostituição, na expectativa de, assim, contactar de forma mais autêntica com a alegada excecionalidade da mulher brasileira. A intimidade a troco de dinheiro apresenta-se-lhes como um cenário indesejado, não tanto pelo dispêndio económico em si, mas pelo facto de subverter a tal normatividade relacional que desejam garantir, podendo mesmo constituir-se como sinal de incapacidade de sedução das mulheres ditas "normais" e, nessa medida, representar um passivo de masculinidade. Ao mesmo tempo, sujeita-os mais intensa e explicitamente às críticas morais que recaem sobre o chamado turismo sexual (Simoni 2014). O dinheiro informa e qualifica as relações (e as identidades dos seus protagonistas), como destaca Simoni (2016) para o cenário turístico cubano.

Nos relacionamentos com mulheres que fazem dos "programas" a sua principal fonte de rendimento, a evacuação da componente monetária torna-se difícil de conseguir, mormente para os turistas mais idosos, com menos condições que os jovens para fazer valer o seu capital estético. Contudo, na tentativa de preservar a honra viril, não são muitos os que, abertamente, admitem pagar para usufruir de companhia feminina, pois, à luz dos seus ideais de masculinidade, o ato de pagamento desvaloriza e, em certa medida, estigmatiza a conquista sexual. O que admitem, sem qualquer complexo, são gastos com as parceiras que se enquadram no que é mais comum acontecer nas relações de género e estão claramente em linha com os valores masculinos hegemónicos do homem-provedor. De modo a reforçar a normatividade do seu comportamento, por vezes fazem questão de destacar que esses gastos resultariam maiores com as mulheres dos seus países. O excerto de uma entrevista em grupo que se segue é elucidativo:

"E2 - Se uma rapariga me diz que é a pagar, já não vou com ela. Mas nem um cêntimo, porque não me agrada pagar a uma mulher! Se está comigo, posso levá-la a comer, a dançar, podemos divertir-nos e posso pagar tudo. Mas o gesto de dar-lhe dinheiro para a levar para a cama, eu não o faço! É contra... eu não o faço. Não me agrada. E, se calhar, durante um dia que 
ande comigo, gasto mais dinheiro que o que gastaria para pagar o programa. Mas o gesto de dar o dinheiro, não... [...]

El - Em Itália são mais prostitutas que aqui, porque, antes de levares uma mulher para a cama, já a levaste para o restaurante, para aqui e para ali. Custa-te mais de dois mil euros, em Itália! Apesar de ser uma mulher normal, é uma prostituta. Este é um quadro da realidade.

E2 - O cortejamento italiano é caro. É caro!" [entrevista com dois turistas italianos: El, 28 anos, e E2, 30 anos]

Considerando o antagonismo que manifestam face à monetarização da intimidade, compreende-se o porquê de preferirem espaços de lazer onde a mercantilização da sexualidade é mais difusa e está mais esbatida, envolta num ambiente idêntico, à primeira vista, ao dos comuns contextos de diversão noturna. Aqueles turistas que, em consequência de repetidas estadias, vão aprofundando o conhecimento do lugar, deixam de frequentar tão amiúde os espaços mais turistificados; até porque eles não se veem simplesmente como turistas (e muito menos como "turistas sexuais") e querem um certo distanciamento face a circunstâncias que os sujeitam a esse rótulo. Ao mesmo tempo, por iniciativa própria ou por intermédio de terceiras pessoas que vão conhecendo, começam a participar em circuitos sociais mais amplos, fora do ambiente turístico. Julgam que, assim, terão mais oportunidades para conhecer mulheres que melhor se enquadram nas suas conceções da normalidade feminina e para construir relações tidas como mais autênticas, baseadas numa maior proximidade afetiva, e através das quais seja possível chegar a novas e mais intensas experiências de intimidade.

Os trajetos de dois dos meus principais informantes - o Gentile (italiano, 48 anos) e o Ambrosini (italiano, 43 anos), ambos com um histórico de mais de uma dezena de prolongadas estadias turísticas na região natalense - são excelentes exemplos desta progressiva ampliação e diversificação das ocasiões de transnacionalização de desejos e afetos. Ao início, durante as primeiras estadias, as suas vivências passionais resumiam-se, quase exclusivamente, ao contexto dos "programas". Fruto de sucessivas deslocações e da progressiva familiarização com as pessoas locais, foram-se integrando em redes de sociabilidade mais amplas e, por essa via, muitas das suas relações íntimas passaram a não estar circunscritas aos "programas", deixando de comportar um perfil comercial, ou, pelo menos, um tão explícito. Da última vez que estiveram no Brasil, a maioria dos seus relacionamentos foram construídos através das respetivas redes sociais, que a Internet tem ajudado a expandir. Para ambos, a grande vantagem das relações íntimas não mercantilizadas advém do facto de lhes proporcionarem experiências de intimidade mais abrangentes, "naturais" e "quentes", no âmbito das quais poderão construir vínculos amorosos mais consistentes. A este propósito, dizia-me o Gentile: 
"Uma coisa é amor, outra coisa é sexo. Estas mulheres que fazem programas são para dar umas voltas no Brasil e não para casar com elas e levá-las para Itália. Eu até posso sair com mulheres da praça (eu gosto de carne crua), mas é mesmo uma coisa só para sexo e nada mais! Não é para namorar. Para isso encontro mulheres fora de Ponta Negra. E com estas o sexo até costuma ser bem melhor, porque elas não estão ali por obrigação".

A intimidade baseada na "relação pura" (Giddens 2002) - isenta de interesses económicos significativos ou de outros interesses externos à própria relação e dependente das retribuições que, intrinsecamente, comporta - representa um ideal de normalidade (Patico 2009) a que aspiram quase todos os turistas europeus em Ponta Negra. Mesmo muitos daqueles que se relacionam com mulheres que fazem "programas" são movidos por desejos de conexão física e emocional autêntica, de que resulte uma "girlfriend experience" (Bernstein 2007), e não deixam de acreditar na possibilidade de construção de relações puras. Ainda que não seja de todo irreal(izável), esta crença tende a alimentarse da "ilusão de 'normalidade" (Piscitelli 2004b) proporcionada pelas parceiras como estratégia da sua própria atividade. Relativamente cientes de que a maioria dos homens com quem convivem procura uma experiência romântica que congregue sexo e afetos, elas tentam agir em conformidade com a narrativa da história de amor e as noções da brasileira como "quente", que integram as metáforas térmicas mobilizadas pelos turistas ("essencialismo estratégico", segundo Simoni 2013: 187), infundindo a ideia de que foram, de facto, seduzidas e conquistadas. Este simulacro de rendição passional, como notam Ribeiro e Sacramento, "deve ser entendido no contexto de uma representação do relacionamento como estando dentro da norma e do socialmente reconhecido como o namoro e o sexo monetariamente desinteressados, partilhada por ambos, gringos e garotas" (2006: 168). Da “ilusão de 'normalidade'" (Piscitelli $2004 b$ ) tendem a resultar alguns devaneios masculinos de conquista, mais ou menos efémeros e contingenciais, e quase sempre permeados por negociações e testes de realidade. ${ }^{5} \mathrm{O}$ enraizamento destes devaneios é notório sobretudo entre os visitantes menos familiarizados com Ponta Negra e com os seus códigos relacionais. Os mais experientes conseguem vislumbrar melhor as subtis demarcações entre diferentes configurações de intimidade.

5 Para esses devaneios muito contribui a inexistência de fronteiras inequívocas a diferenciar a relação íntima pessoal e a relação comercial. Nos contextos mais mercantilizados, as trabalhadoras sexuais, por norma, usam o preservativo com os seus clientes, recusam o beijo na boca e estipulam um preço pelos serviços que prestam (Ribeiro et al. 2007). De forma distinta, no âmbito dos "programas", a utilização do preservativo não é tão categórica, o beijo na boca é uma prática comum e o pagamento nem sempre obedece a um padrão rígido e monetarizado. 


\section{INDEXAÇÕES TÉRMICAS TRANSATLÂNTICAS}

A normalidade passional que os turistas buscam em Ponta Negra está, de modo variável e ambíguo, articulada com ideias da feminilidade (e da sexualidade) brasileira como exótica, "aberta", "quente" e genuína, ainda não adulterada pela emancipação que, alegadamente, tem estado na origem do fechamento da mulher europeia, da sua frieza e escassa disponibilidade para investir nas relações íntimas. O Brasil é por eles associado a uma suposta genuinidade feminina que sentem estar a desaparecer na Europa e a assumir traços identitários usualmente associados ao masculino. O que ouvi de um português (70 anos), turista/residente em Ponta Negra, é elucidativo: “Ó pá, eu acho que a mulher aqui é mais feminina... mais do que a portuguesa. A mulher portuguesa, para mim, tornou-se machona, é mais possessiva. Eu noto isso! Gosta de controlar, gosta de mandar. Mas acho que aqui são mais meigas, são mais meigas". A noção de autenticidade (Piscitelli 2004c) tende a remeter, deste modo, para a ideologia patriarcal da mulher dócil, como se pode constatar, aliás, num outro testemunho: "Aqui [Brasil], as raparigas são belíssimas, porque são pessoas humildes. Como carácter, aqui agradam-me muito mais. As mulheres da América do Sul são mais humildes. Aqui, uma bela rapariga, afetuosa, verdadeiramente..." [turista italiano, 28 anos].

A conceção da brasileira como mulher verdadeiramente feminina incorpora ainda atributos etnossexuais que remetem para as supostas carga erótica "natural" e disponibilidade para o sexo, associando-as à própria corporeidade. São bastante frequentes, por exemplo, comentários do género: "para elas, o sexo é natural" ou "todo o corpo delas é sexo". A categoria "quente" é usada recorrentemente para qualificar a sua sexualidade, constituindo, ao mesmo tempo, o polo comparativo com base no qual as mulheres europeias são consideradas mais "frias", mais conservadoras, menos "naturais", incapazes de criar um ambiente erótico tão intenso e de corresponder ao desejo masculino de expansão de horizontes sexuais:

"Eu acho que em Portugal - ou eu estou desatualizado - não havia esta abertura que há aqui. A mulher lá, quando um gajo começa a forçar, é mais retraída: 'Eu não sou dessas!' Mas é... mas às vezes também é falso, porque elas são como as outras. Agora as brasileiras dão mais abertura... a mulher portuguesa não. E depois... sexualmente, enquanto que na Europa ainda há aquele conceito púdico e religioso papai e mamãe, a mulher aqui não. A mulher aqui gosta de fantasias, tem... sexualmente tem uma cultura indígena que os jesuítas não lhe conseguiram tirar. $\mathrm{O}$ sexo faz parte da cultura dela" [turista/residente português, 70 anos].

A generalidade dos turistas identifica o papel ativo e descomplexado da mulher brasileira na gestão das questões do corpo e da sexualidade como um 
fator decisivo para a construção de cenários íntimos espontâneos e envolventes, isentos de muitos dos fantasmas morais que ainda vislumbram na vida privada dos seus países. No Brasil admitem, por isso, sentir-se particularmente "soltos" - isto é, menos constrangidos pelos preceitos culturais da vergonha com o corpo e o sexo - para experimentar o prazer em função das suas predisposições sexuais mais subjetivas, estabelecendo uma relação mais distendida com a moralidade sexual e fazendo jus à antiga noção colonial europeia de que "não existe pecado a sul do Equador" (Barléu 1940 [1647], citado em Holanda 1990 [1936]: 212). ${ }^{6}$ A própria viagem, sobretudo quando implica uma deslocação transnacional, cria, por si só, condições favoráveis a transformações de subjetividade, suscitando no turista a sensação de que "he is freed from standards of behavior imposed by respectable women back home" (Enloe 1989, citado em Chow-White 2006: 895).

No longo relato que se segue, o Gentile descreve de forma bastante expressiva como aquilo que considera ser a "naturalidade" e a participação empenhada da mulher brasileira na relação com o parceiro são fundamentais para vivências amplas de intimidade, sem grandes reservas e inibições, possibilitando uma maior harmonia na equação masculina "sexo versus emoção":

"A italiana abre as pernas e pouco mais. A brasileira participa, é muita mais ativa. Antes eu até achava normal que uma mulher estivesse parada. Eu continuava e pronto. Agora não. Agora, se uma mulher não participar, eu não continuo. Já me habituei com a mulher brasileira! E ela não tem tabus. Pouco tempo depois de conhecer a Cleuza [namorada], uma vez encontrei-a de pernas abertas, no sofá, a depilar os pelos da vagina. Eu cheguei e fiquei um pouco envergonhado, mas ela nada... continuou normalmente. A minha ex-companheira italiana, mesmo depois de morar com ela vários anos, tinha de se fechar na casa de banho para fazer isso. É desta naturalidade que eu gosto na mulher brasileira, de não ter tabus em relação ao sexo, ao corpo... e ao corpo do homem que está com ela. Lembro-me que, uma vez, num domingo, quando estava em casa da Cleuza no Brasil, ela começou a tirar os pontos negros do meu corpo, a arrancar os pelos das minhas orelhas e do nariz com uma pinça. Uma mulher italiana dificilmente faria isto, ainda por cima num domingo. A minha ex-namorada não fazia. Ia passear o cão ou fazer outra coisa, mas isso não. Outro exemplo. Da segunda vez que me encontrei com a Cleuza, depois de me ir buscar ao aeroporto, para o carro, vai à farmácia e traz um saco. Eu pergunto-lhe se está doente e ela, brincando, diz-me que

6 Procurando justificar a existência nos trópicos de manifestações eróticas e sexuais inimagináveis para o contexto europeu, o historiador e teólogo holandês Caspar Barlaeus (Barléu), no seu relato de 1647, destacava a crença europeia de que "não existe pecado a sul do Equador. [...] Como se a linha que divide o mundo em dois hemisférios também separasse a virtude do vício" (citado em Holanda 1990 [1936]: 212). 
aquilo é para um italiano que recebe hoje em sua casa. Eu abro o saco e vejo um monte de camisinhas, de cremes e gel. E ela sempre com naturalidade, sem vergonha. É deste à-vontade, desta naturalidade que eu gosto na brasileira. Não há tabus. É tudo sem fazer problemas e mistérios".

As valorações implícitas na avaliação masculina do modo como as mulheres dos dois lados do Atlântico lidam com as questões da intimidade (sobretudo da sexualidade) - positivas face às brasileiras e depreciativas em relação às europeias - são permeadas por algumas ambivalências (Piscitelli 2004a) e podem, por vezes, sofrer alterações significativas quando se considera o matrimónio. Recordo-me dos discursos de alguns informantes a ressalvar que, embora sem os mesmos predicados sexuais que as brasileiras e apesar das mudanças nas identidades e relações de género, ainda haveria europeias "melhores para casar" e "mais adequadas para a vida de família". Nas suas próprias palavras, estas últimas seriam "mais trabalhadoras", "mais responsáveis" e, sexualmente, "mais fiéis". Reproduz-se, assim, à escala transatlântica, uma visão dicotómica da feminilidade - mulher alvo de desejo sexual versus mulher-esposa-mãe, alvo de afeto (Silva 2003) - decorrente da proeminente ideologia masculina da intimidade como esfera fragmentada entre sexo e emoção. Neste plano transnacional, o antagonismo entre a mulher sexualmente desejável e a mulher virtuosa, ambicionada para amar como esposa e mãe, tende a ser estruturado em função de traços constitutivos da própria identidade nacional: a primeira é associada ao "calor" e à exuberante sensualidade da brasilidade e a segunda à alegada maior "frieza" racional e recato dos países europeus.

Porém, são muitos os turistas europeus, em particular aqueles cujos relacionamentos extrapolam o âmbito dos "programas", que organizam a sua vida passional com base nesta mesma dicotomia sem a anexar, todavia, aos estereótipos veiculados pela nacionalidade. Aliás, no seu entender, a multiplicidade de perfis femininos no Brasil e as características singulares da feminilidade brasileira tornam relativamente fácil a concretização de diferentes aspirações, desde as mais orientadas para a sexualidade àqueloutras que (também) contemplam projetos de conjugalidade e família. Estas mesmas aspirações nem sempre pressupõem diferentes mulheres e relações para se materializarem. Como vimos atrás, no caso do Gentile, sexo e emoção podem coexistir de forma mais ou menos equilibrada na mesma relação. Quando a coexistência é inviável, alegadamente, as alternativas possíveis serão muitas, como se pode deduzir da observação feita por um turista espanhol (43 anos): "No Brasil há mulheres para o sexo e também boas mulheres para casar. Há mulheres muito diferentes... e há muitas!" ${ }^{7}$ Esta ideia de variedade (simultaneamente física e

7 Umas e outras são sinalizadas em categorias produzidas pela sociedade brasileira e já assimiladas por bastantes turistas. Rótulos como "garota de programa", "rapariga" e "piriguete" [continua] 
social) na quantidade, impulsionada pela conceção amplamente difundida da brasilidade como resultado de sucessivas misturas raciais, constitui mais uma fonte da sua atração pelo Brasil, percebido como "terra de mulheres para todos os gostos" [turista espanhol, 43 anos] e uma espécie de caleidoscópio de possibilidades de intimidade em comparação com os países europeus.

O fascínio pela diversidade de possíveis parceiras e cenários passionais é indissociável do desejo de acesso ao exotismo feminino que as noções dominantes sobre a identidade brasileira evocam. Este desejo não pressupõe, inevitavelmente, configurações relacionais fundadas numa significativa alteridade física (Piscitelli 2004a). Quer isto dizer que não podemos tomar como certa e inquestionável a atração masculina pelas mulheres cujas diferenças face às europeias se inscrevem nos próprios corpos, sob a forma de marcadores como a cor da pele. Para muitos homens, a dissemelhança fenotípica não representa, necessariamente, uma condição fundamental de atração. Aliás, quando os informantes me falavam dos traços físicos femininos que mais lhes suscitam fascínio, bastantes faziam referência a características não muito divergentes das que compõem o(s) fenótipo(s) predominante(s) nos seus países. Para exemplificar a sua preferência, um italiano (48 anos) mostrou-me uma foto da atriz britânica Claire Forlani, ilustrando, assim, o seu "tipo ideal de mulher", e destacando ainda o facto de a sua ex-mulher brasileira, que conheceu em Ponta Negra, também ser "completamente diferente do estereótipo da brasileira" ["mulata"]. Não podemos esquecer, porém, que estas idealizações tendem a refletir a dicotomia masculina da feminilidade. Podem, por isso, assumir uma certa ambivalência, fazendo com que o perfil físico feminino objeto de maior e descomplexado desejo sexual nem sempre corresponda ao perfil desejado para um projeto de aliança. Em princípio, este último perfil não comporta uma diferença exótica racializada e sexualizada tão acentuada como o primeiro.

Independentemente destas nuances e mais do que coligada a marcadores corporais, a alteridade desejada pelos europeus remete, acima de tudo, para construções simbólicas do feminino enquanto parte integrante da própria identidade do Brasil. É sobretudo em função da categoria nacionalidade, como adverte Piscitelli (2008), e dos estereótipos que lhes estão associados - como é o caso da noção de "caliente" para Cuba (Simoni 2013) -, conferindo singularidade exótica, erótica e emocional à mulher brasileira, que os turistas em Ponta Negra desejam novos enquadramentos e formas relacionais para construir a

[continuação] qualificam mulheres alvo de uma forte conotação sexual e cujo comportamento rompe com os valores de género dominantes. Nos antípodas encontramos a categoria "moça de família", utilizada para fazer referência a mulheres que se enquadram nos parâmetros hegemónicos da feminilidade e que correspondem ao modelo de mulher normal que os turistas mais desejam, em especial quando têm em perspetiva uma relação conjugal. 
sua vida íntima. Para tal, pressupõem ser possível (re)encontrar nos trópicos uma suposta autenticidade feminina e de intimidade (Piscitelli 2004b, 2004c) que a Europa estará a perder, ainda que o objeto da sua procura lhes possa surgir, acima de tudo, como performance mais ou menos contingencial, sob a forma ilusória de "autenticidade encenada" (MacCannell 1973). Tal como muitos outros turistas, também estes têm um olhar romântico - "romantic gaze" (Urry 1996) - sobre o lugar turístico e parecem manifestar "ansiedade sobre a autenticidade" (Harkin 1995, citado em Abbink 2004: 269). Compreende-se, assim, o facto de considerarem a ambicionada alteridade na intimidade como algo que só será verdadeiramente possível no Brasil. O relato de Baldovino, um advogado italiano de 48 anos que acompanhei em Ponta Negra e em Milão, é esclarecedor:

"Uma coisa é a brasileira lá [Brasil], outra coisa é aqui, na Europa. Eu posso falar... eu já tive mulher brasileira lá e mulher brasileira aqui, em Milão. Lá, elas nos parecem mais tradicionais, mais calmas, mais calorosas. Aqui ficam mais parecidas com as italianas, um pouco mais frias. Ficam mais consumistas... elas já são no Brasil, mas aqui em Milão, elas estão na sua ecologia natural. E a minha relação com a brasileira que conheci aqui em Milão não deu certo porque nós tínhamos poucas coisas parecidas... em comum. Ela já estava aqui há mais de dez anos. Ela era muito consumista e eu não. Era muito superficial... não dava para ter conversas mais complexas. A única coisa que tínhamos em comum era o ski. Eu gosto muito de fazer ski e ela também gostava. A nossa relação também foi-se mantendo porque... apesar de mais parecida com a italiana, o calor da mulher brasileira que vive na Europa nunca desaparece completamente. Há sempre alguma coisa que fica. Só que isto não chegava para manter a relação. Era pouco!”

Segundo este exercício masculino de dedução do valor da brasileira fora do Brasil, o que parece estar em causa é uma profunda alteração e corrupção dos atributos que alegadamente lhe conferem autenticidade, resultante da mudança do cenário geográfico em que se confrontam e cruzam as fronteiras da alteridade. Aos olhos dos homens europeus, o "calor" da feminilidade tropical perderse-á na travessia atlântica e no inevitável contacto com ambientes mais "frios". Assim, mesmo tendo acesso a mulheres brasileiras na Europa, muitos procuram experiências passionais na origem, na expectativa de que aí essas experiências lhes proporcionem um valor acrescido de exotismo e genuinidade.

\section{O CALOR QUE FALTAVA}

As deslocações turísticas masculinas para Ponta Negra, tal como muitas outras mobilidades, não são inócuas quanto ao modo como os sujeitos entendem, 
cumprem e apresentam as suas identidades de género (Cresswell e Uteng 2008). Os trânsitos em causa estabelecem mudanças de enquadramentos e de subjetividades, favorecendo experiências de masculinidade tidas como dificilmente concretizáveis nos países europeus. Investido de uma densa polissemia, o "calor" brasileiro é, mais uma vez, apropriado metaforicamente pelos turistas para indiciarem o que lhes falta(va) para uma maior convergência face às idealizações de intimidade e do que é ser homem. Aqui, como na generalidade dos casos, a metáfora representa "uma asserção sobre uma situação disforme. Ela diz que algo muito mais concreto e apreensível - uma pedra rolando, um pássaro na mão - é equivalente aos elementos essenciais em uma outra situação que temos dificuldade em entender" (Fernandez 1986, citado em Geest e Whyte 201 1: 464). Quando interpelava os meus interlocutores europeus sobre as razões da escolha do destino turístico em causa, as suas respostas remetiam quase sempre para metáforas térmicas que, simbolicamente, sinalizam contrastes transatlânticos e possibilidades de reajustamento identitário decorrentes da deslocação para uma ecologia "mais quente".

Nestas metáforas, o calor do clima tropical é, por analogia e reflexo, e em oposição ao frio da Europa, tomado como referência de qualificação positiva do lazer, do convívio masculino e das experiências de intimidade que o Brasil proporciona. Constitui, portanto, um denominador sintético e simbólico de circunstâncias sociais que, em princípio, podem propiciar o reforço dos processos de homossociabilidade - decisivos na produção e legitimação da identidade viril - e a (re)capitalização de valores dominantes de masculinidade; afinal, "Men who are not exceptionally privileged at home are able to step closer to the ideal of hegemonic masculinity while on holiday" (Rivers-Moore 2012: 866). Além dos valores viris decorrentes do incremento do estatuto socioeconómico proporcionado pela deslocação transatlântica, ganham particular relevância os valores associados às celebrações hedonistas que o próprio contexto estimula, às competências de conquista passional e de expressão da sexualidade e, inclusivamente, às capacidades de escolha e sedução da "mulher certa" para constituir família.

A estadia em Ponta Negra corresponde a um tempo de grande interação e cumplicidade masculina, isento de muitos dos constrangimentos presentes nos países de origem. O afrouxamento das obrigações e restrições quotidianas representa uma excelente oportunidade para se reavivarem laços de comunhão a que as responsabilidades da vida adulta retiraram algum cabimento e que a hierarquia e competição do mercado de trabalho colocou sob intensa pressão (Kruhse-Mountburton 1995): "Na Europa estamos baseados no trabalho, trabalho, trabalho! Aqui não. Aqui deixa-se o trabalho. São modos de viver diferentes. Aqui é tudo totalmente diferente. Aqui é só para os amigos e divertimento!" [turista italiano, 43 anos]. Alguns referem o companheirismo viril como uma finalidade em si mesma da própria deslocação turística. Por vezes, e 
seguindo uma retórica masculina bastante comum, a convivência com os pares é alvo de uma (sobre)valorização que aparenta sobrepor-se à importância atribuída a outras experiências que, à partida, poderiam considerar-se alvo de um desejo muito maior: "O meu grande objetivo não é vir para aqui pelo sexo. Eu quero relaxar, estar com os meus amigos e, se encontrar uma rapariga, é bom ter sexo, mas não é realmente importante" [turista holandês, 30 anos]. Independentemente da importância que lhes é atribuída, as conquistas heterossexuais são objeto de permanente discussão e escrutínio entre amigos. Nessa medida, constituem matéria nuclear das práticas de virilidade, sobretudo discursivas, que fundam o sentido de pertença ao grupo e lhe conferem atributos identitários.

O ambiente homossocial em Ponta Negra evidencia muitas das características que Maffesoli (1998 [1988]) atribui ao "tribalismo pós-moderno": o presenteismo vitalista, o orgiasmo social, o hedonismo e os excessos festivos. A calorosa celebração do momento convida os turistas a formas de apresentação do eu, disposições e comportamentos pouco frequentes nas suas vidas na Europa, mesmo em tempos e espaços de lazer. Estas manifestações ganham particular significado entre os menos jovens, que parecem fruir o tempo que passam no Brasil como uma experiência nostálgica de revivalismo de manifestações de masculinidade e da juventude que tiveram ou desejavam ter tido. A forma como, frequentemente, se vestem e os adereços que usam (v.g. lenços de cabeça "à pirata", colares coloridos), o modo arrojado como alguns conduzem as motos estilo Vespa a expressão desinibida e afirmativa da corporeidade, as conquistas passionais e a constante proclamação do vigor físico junto dos pares são exemplos que apontam para estéticas e performances mais associadas à juventude. A este propósito, lembro o comentário feito pelo Giacomo (italiano de 58 anos, turista/residente) quando viu passar por nós numa Vespa, a uma velocidade considerável, dois conhecidos, também italianos, com mais de 60 anos, usando bonés com a pala para trás e óculos de sol: "Esses vêm para cá e morrem sem se aperceber!” Com isto queria dizer que Ponta Negra lhes proporciona um entusiasmo revigorante, capaz de mitigar a intuição subjetiva do fluir do tempo e do envelhecimento.

A diversão, as saídas noturnas e os relacionamentos amorosos, geralmente com mulheres mais novas, parecem funcionar para estes homens como uma espécie de elixir da juventude que lhes permitirá recuperar formas de masculinidade desvanecidas e experienciar um sentimento de empoderamento e autoestima viril (Chow-White 2006; Kempadoo 1999; Kruhse-Mountburton 1995; O'Connell-Davidson 2001; Rivers-Moore 2012). A intimidade é um palco central destas alterações transnacionais na subjetividade masculina e na afirmação da identidade de género. É nesse palco que os turistas perseguem vivências que consideram de difícil concretização na Europa, desde logo pelos alegados constrangimentos decorrentes de feminilidades tidas como 
"demasiado emancipadas" e porque as mulheres mais valorizadas lhes são praticamente inacessíveis, por razões de ordem económica, estética, relacional e/ ou de estatuto social. Com a deslocação transatlântica asseguram ganhos relativos de capacidade económica, de capital simbólico e até de atratividade, ${ }^{8}$ de que decorrem transformações significativas nas coordenadas de configuração da intimidade. Fazendo uso da sua habitual eloquência, o Giacomo ilustrou esta questão assim: "Como é que um homem como eu, com 58 anos, vai arranjar uma mulher de 20 e poucos anos na Europa, uma velina ${ }^{9}$ Só se tiver um Ferrari, só se for rico. O Briatori pode! Com o dinheiro, pode. Nós temos de vir para cá. Aqui, eu posso ter a minha Naomi [Campbell]! Cá, sou como o Briatori e não sou milionário".

Em Ponta Negra, a conquista de mulheres que se enquadram em perfis desejados pode, em muitos casos, ser "ilusória" e estrategicamente instrumentalizada pelas parceiras, por motivos materiais. Contudo, essa conquista não deixa de contribuir para a emergência de metamorfoses significativas na forma como a masculinidade é experienciada. As mais relevantes, segundo os próprios turistas, circunscrevem-se à sexualidade, eixo nevrálgico da (auto)afirmação dos valores hegemónicos da identidade masculina (Almeida 1995; Connell 1995):

"Um gajo aqui puxa, com o calor... tanto para elas como para nós. A conversar com um amigo português de João Pessoa [capital do estado vizinho da Paraíba], ele diz-me: 'Ó pá, eu chego aqui e tenho tesão e lá em Portugal eu não tinha, já não ligava puto'. Comigo é o mesmo. [...] Agora, eu também me libertei um bocado. Como se diz em Portugal, soltei um bocado a franga. Aqui virei ao contrário. Eu aqui mudei. Parece que estou a viver uma segunda meninice... um pouco" [turista/residente português, 70 anos].

Em comparação com a sua vida íntima na Europa, estes homens sentem-se rejuvenescidos, mais desejados e com maior predisposição para o erotismo e a atividade sexual; capazes de fruir e de proporcionar um prazer que os faz sentir verdadeiramente homens. ${ }^{10}$ Quando os instava a encontrar explicações para as mudanças nas suas vivências pessoais da sexualidade e da masculinidade, o "calor" (do clima e da mulher brasileira) era, recorrentemente, invocado como o principal e mais imediato fator justificativo. Numa correlação antitética face ao "frio" europeu, o "calor" brasileiro é tido como elemento positivo

8 A brancura e os olhos claros dos europeus, por exemplo, são alvo de grande valorização estética por parte das mulheres locais.

9 Velina: designação italiana para a mulher que corporiza cânones de beleza e sensualidade amplamente mediatizados.

10 Semelhante alteração nas "subjetividades eróticas" foi constatada por Frohlick (2008) entre mulheres ocidentais em turismo na Costa Rica. 
de irradiação de energia revigorante. O relato que se segue demonstra-o com particular expressividade:

"Ela [a companheira] é que me está a dar a idade, ela é que me está a pôr novo. Não me estou a pôr velho..., novo! Eu, ontem, funcionou a 100\%, $500 \%$ ! E hoje venho mais o meu primo aqui [praia de Ponta Negra] a pé, deixo ali a coisa, a $t$-shirt e a sandália, e estás a ver? Todos os órgãos estão a funcionar a 500\%. [...] Em Portugal tinha duas, mas não estava a funcionar bem. Uma com 40 anos e outra mais velha. Tinha lá uma da minha idade, 70 anos... Mas a máquina dela, lá em Portugal, não funciona como a minha. A desta aqui funciona por causa do calor. Isso faz tanta diferença, tanta diferença! A máquina dela é mais quente. [...] A mulher brasileira mexe mais um bocado... mexe mais um bocado e é mais calorenta. A mulher brasileira é mais calorenta! Tem mais calor. E funciona bem ali... trabalha bem! [...] Aqui, estou a 500\%. Elas [as mulheres] é que me fazem a mim novo. É tanto que eu digo que aqui é o hospital da velhice. [...] Ó pá, mas o Brasil é só para não apanhar lá frio [em Portugal]. É pela questão do frio. Isto aqui é que me dá saúde, mesmo! Cada vez estou mais novo. E de que maneira! Com dez anos de diferença. 'Tá bem que elas [brasileiras] também estão lá [em Portugal], mas é o clima... o clima é que manda! O calor e essas coisas todas..." [turista português, 71 anos].

É caso para dizer, como sugere poeticamente Littlewood (2001) no seu livro Sultry Climates: Travel and Sex since the Grand Tour, que o erotismo e a sexualidade são mais intensos onde o clima é cálido. Mas não é apenas prazer sexual que os europeus procuram no "calor" de Ponta Negra. Também é afeto, romantismo e aliança, inclusivamente quando os relacionamentos assumem um perfil mais comercial. Encontrar uma mulher com as características consideradas adequadas para casar e constituir família é uma aspiração de grande relevância na ideologia da masculinidade da maior parte dos europeus que conheci. Esta aspiração é sinalizada, mais uma vez, através de uma metáfora térmica na qual tendem a expressar preferência pela mulher brasileira, considerando-a "mais calorosa" 11 (meiga, humilde, pouco emancipada, orientada para a família) que a europeia; ainda que, num registo de manifesta ambiguidade, possam também apontar à primeira, em particular quando conotada com a prostituição, características que remetem para o facto de, supostamente, ser interesseira e menos confiável e responsável.

11 Neste contexto, o calor atribuído à mulher brasileira indicia, principalmente, propriedades de género pouco sexualizadas e que se enquadram no termo emocional da dicotomia masculina da feminilidade de que falava atrás. De modo distinto, o calor que lhe é atribuído quando é qualificada como "quente" configura, quase sempre, uma representação hipersexualizada. 
Seja na intimidade ou na homossociabilidade que acompanham as práticas de lazer, o "calor" do Brasil é construído pelos turistas como o elemento compensador e revivalista que lhes permite resgatar sensações e expressões de masculinidade adormentadas pelo "frio" da Europa. Porém, esta experiência transatlântica de intensificação da virilidade não deixa de estar associada, amiúde, às já mencionadas ilusões passionais de normalidade e conquista (Piscitelli 2004b; Ribeiro e Sacramento 2006). Por outro lado, encontra-se vinculada a subjetividades sem correspondência significativa em termos de reconhecimento social, como ressalva O'Connell-Davidson (2001) para os turistas ocidentais na República Dominicana. Aliás, a viagem para destinos sexualizados é bastante associada à procura de sexo comercial, pelo que as experiências transnacionais de intimidade, independentemente da forma que assumem, tendem a ser estigmatizadas e citadas por terceiros, sobretudo concidadãos, como argumento de qualificação negativa da masculinidade. Apesar de tudo, isto não inibe os visitantes de Ponta Negra, já depois de regressados à Europa, de evocar constantemente memórias da estadia e de manifestar a sua nostalgia pelo ambiente quente dos trópicos.

\section{CONSIDERAÇÕES FINAIS}

Os discursos e as práticas dos turistas europeus em Ponta Negra evidenciam desejos de construir alternativas às experiências de convivência íntima na Europa, consideradas pouco satisfatórias, e de encontrar circunstâncias favoráveis à (re)afirmação de identidades masculinas que a emancipação feminina ocidental e o peso das obrigações quotidianas alegadamente terão entorpecido. Na maioria dos casos, esta demanda de mudanças não pressupõe, à partida, ruturas ou transformações identitárias radicais. Trata-se, antes, de um processo que tende mesmo a ser impulsionado pelas noções hegemónicas de intimidade e de masculinidade dos próprios turistas, pelo que será adequado associá-lo à tentativa de alargamento, à escala transnacional, do horizonte de oportunidades de concretização daquelas noções. Estes homens anseiam, assim, por cenários íntimos e de convivência homossocial que lhes proporcionem vivências de género, configurações passionais e possibilidades afetivas e conjugais tidas como mais convergentes com as suas subjetividades e pretensões, embora estas não sejam fixas e possam transfigurar-se de modo mais ou menos significativo em função da própria experiência turística em Ponta Negra.

Imbuídos de representações exóticas e sensuais do Brasil, sobretudo do Brasil no feminino - inscritas no imaginário sexualizado e racializado dos períodos colonial e pós-colonial -, e congregando em geometrias variáveis distintos desejos e projetos, os turistas europeus esperam encontrar "calor" no Nordeste brasileiro: (i) manifestações autênticas, dóceis e não emancipadas 
de feminilidade e, assim, concretizar cânones de género, paixão, conjugalidade e família que julgam mais dificilmente realizáveis no continente europeu; (ii) um exotismo sexual na origem, em "estado puro", alimentado pelo fogo dos trópicos, e, supostamente, ainda não mercantilizado e/ou arrefecido como o que lhes é proporcionado na Europa por mulheres brasileiras; (iii) intensas experiências homossociais e um ambiente cálido que os resgate de quotidianos monocórdicos e de um certo inverno viril que alegam viver nos países de origem.

As narrativas das mudanças na esfera da intimidade associadas à deslocação turística para Ponta Negra tendem a ser alicerçadas no lastro figurativo de metáforas térmicas, através das quais o "calor" revitalizante dos trópicos é, de forma sistemática, contrastado com o "frio" debilitante do continente europeu. Nestas metáforas é mobilizada a construção semântica dominante do Brasil como destino triplamente "quente": do ponto de vista climático, social (v.g. afetuosidade) e eróticossexual. Aliás, o adjetivo é, repetidamente, utilizado com esta diversidade de sentidos, tal como o seu oposto é associado, em simultâneo, às condições de clima, à sociabilidade e à sexualidade na Europa. $\mathrm{O}$ contraste eminentemente relacional dos polos térmicos destes empreendimentos metafóricos configura o eixo simbólico por via do qual são produzidas as representações e indexados os desígnios (e as respetivas justificações) que dão corpo às narrativas das experiências passionais transatlânticas. Nas suas narrativas, os turistas europeus indiciam uma nítida aversão às "intimidades frias" do "capitalismo emocional", no qual os discursos e práticas económicas e sentimentais se pressupõem mutuamente (Illouz 2007: 5). Porém, as intimidades que encontram no Brasil, ainda que semanticamente colonizadas por noções cálidas com grande densidade histórica, não deixam de estar permeadas, de forma mais ou menos camuflada, por lógicas materiais. Afinal, como notam Adelman (201 1) e Zelizer (2005), além de poética, os vínculos íntimos, inevitavelmente, também comportam política e economia. 


\section{BIBLIOGRAFIA}

ABBINK, Jon, 2004, "Tourism and its discontents: Suri-tourist encounters in Ethiopia”, em Sharon Gmelch (org.), Tourists and Tourism: A Reader. Long Grove, Waveland Press, 267-287.

ADELMAN, Miriam, 2011 , "Por amor ou por dinheiro? Emoções, discursos, mercados", Contemporânea: Revista de Sociologia da UFSCar, 1 (2): 117-138.

ALMEIDA, Miguel Vale de, 1995, Senhores de Si: Uma Interpretação Antropológica da Masculinidade. Lisboa, Fim-de-Século Edições.

ALMEIDA, Miguel Vale de, 2004, Outros Destinos: Ensaios de Antropologia e Cidadania. Porto, Campo das Letras.

BARLÉU, Gaspar, 1940 [1647], O Brasil Holandês sob o Conde João Maurício de Nassau. Rio de Janeiro, Serviço Gráfico do Ministério da Educação.

BECK, Ulrich, e Elisabeth BECK-GERNSHEIM, 2004, The Normal Chaos of Love. Cambridge, Polity Press.

BERNSTEIN, Elizabeth, 2007, Temporarily Yours: Intimacy, Authenticity, and the Commerce of Sex. Chicago e Londres, The University of Chicago Press.

BRENNAN, Denise, 2004, "When sex tourists and sex workers meet: encounters within Sosúa, the Dominican Republic", em Sharon Gmelch (org.), Tourists and Tourism: A Reader. Long Grove, Waveland Press, 303-315.

CABEZAS, Amalia, 2009, Economies of Desire: Sex and Tourism in Cuba and the Dominican Republic. Filadélfia, Temple University Press.

CHOW-WHITE, Peter, 2006, "Race, gender and sex on the net: semantic networks of selling and storytelling sex tourism”, Media, Culture \& Society, 28 (6): 883-905.

CONNELl, Robert, 1995, Masculinities: Knowledge, Power and Social Change. Berkeley, University of California Press.

CRESSWELL, Tim, e Tanu UTENG, 2008, "Gendered mobilities: towards an holistic understanding”, em Tanu Uteng e Tim Cresswell (orgs.), Gendered Mobilities. Aldershot, Ashgate, $1-12$.

ENLOE, Cynthia, 1989, Bananas, Beaches and Bases: Making Feminist Sense of International Politics. Londres, Pandora.

FERNANDEZ, James, 1986, Persuasions and Performances: The Play of Tropes in Culture. Bloomington, Indiana University Press.

FERNANDEZ, James (org.), 1991, Beyond Metaphor: The Theory of Tropes in Anthropology. Stanford, Stanford University Press.

FISCHER, Michael, 2012, "On metaphor: reciprocity and immunity", Cultural Anthropology, 27 (1): 144-152.

FROHLICK, Susan, 2008, “'I'm more sexy here': erotic subjectivities of female tourists in the 'sexual paradise' of Caribbean Costa Rica”, em Tanu Uteng e Tim Cresswell (orgs.), Gendered Mobilities. Aldershot, Ashgate, 129-142.

FROHLICK, Susan, 2010, “The sex of tourism? Bodies under suspicion in paradise”, em Julie Scott e Tom Selwyn (orgs.), Thinking through Tourism. Oxford e Nova Iorque, Berg, 5 1-70.

GEEST, Sjaak Van Der, e Susan WHYTE, 2011 , "O encanto dos medicamentos: metáforas e metonímias”, Sociedade e Cultura, 14 (2): 457-472.

GIDDENS, Anthony, 2001 [1992], Transformações da Intimidade: Sexualidade, Amor e Erotismo nas Sociedades Modernas. Oeiras, Celta. 
GIDDENS, Anthony, 2002, Modernidade e Identidade. Rio de Janeiro, Jorge Zahar Editor. GOMES, Danielle, et al., 2010, "Acuarela multicolor: Brasil pintado por los turistas extranjeros", Estudios y Perspectivas en Turismo, 19: 607-655.

HARKIN, Michael, 1995, "Modernist anthropology and tourism of the authentic", Annals of Tourism Research, 22: 650-670.

HOEFINGER, Heidi, 2013, Sex, Love and Money in Cambodia: Professional Girlfriends and Transactional Relationships. Abingdon e Nova Iorque, Routledge.

HOLANDA, Sérgio B., 1990 [1936], Raizes do Brasil. Rio de Janeiro, José Olympio.

ILLOUZ, Eva, 1999, “The lost innocence of love: romance as a postmodern condition”, em Mike Featherstone (org.), Love \& Eroticism. Londres, Sage, 161-186.

ILlOUZ, Eva, 2007, Cold Intimacies: The Making of Emotional Capitalism. Cambridge (UK) e Malden (MA), Polity Press.

KEMPADOO, Kamala (org.), 1999, Sun, Sex, and Gold: Tourism and Sex Work in the Caribbean. Lanham, Rowman \& Littlefield.

KIMMEL, Michael, 2004, "Metaphor variation in cultural context: perspectives from Anthropology", European Journal of English Studies, 8 (3): 275-293.

KING, Russell, 2002, “Towards a new map of European migration”, International Journal of Population Geography, 8: 89-106.

KRUHSE-MOUNTBURTON, Suzy, 1995, "Sex tourism and traditional Australian male identity”, em Marie-Françoise Lanfant, John Allcock e Edward Bruner (orgs.), International Tourism: Identity and Change. Londres, Sage, 192-204.

KUMMELS, Ingrid, 2005, "Love in the time of diaspora: global markets and local meanings in prostitution, marriage and womanhood in Cuba", Iberoamericana, 5 (20): 7-26.

LAKOFF, George, e Mark JOHnSON, 2003 [1980], Metaphors We Live By. Chicago, The University of Chicago Press.

LITTLEWOOD, Ian, 2001, Sultry Climates: Travel and Sex since the Grand Tour. Londres, John Murray.

MACCANNELL, Dean, 1973, "Staged authenticity: arrangements of social space in tourist settings", American Journal of Sociology, 73 (3): 589-603.

MAFFESOLI, Michel, 1998 [1988], O Tempo das Tribos: O Declínio do Individualismo nas Sociedades de Massa. Rio de Janeiro, Forense Universitária.

NAGEL, Joane, 2003, Race, Ethnicity, and Sexuality: Intimate Intersections, Forbidden Frontiers. Oxford, Oxford University Press.

O'CONNELL-DAVIDSON, Julia, 2001, "The sex tourist, the expatriate, his ex-wife and her 'other': the politics of loss, difference and desire", Sexualities, 41 (1): 5-24.

ORTEGA Y GASSET, José, 2005 [1917-1925], Obras Completas: Tomo III. Madrid, Taurus.

PATICO, Jennifer, 2009, "For love, money, or normalcy: meanings of strategy and sentiment in the Russian-American matchmaking industry”, Ethnos, 74 (3): 307-330.

PINA-CABRAL, João de, 2017, World: An Anthropological Examination. Chicago, HAU Books.

PISCITELLI, Adriana, 2004a, “On 'gringos' and 'natives': gender and sexuality in the context of international sex tourism”, Vibrant: Virtual Brazilian Anthropology, 1 (1-2): 87-114, disponível em < http://www.vibrant.org.br/issues/vl n l/adriana-piscitelli-on-gringos-andnatives/ > (última consulta em junho de 2019).

PISCITELLI, Adriana, 2004b, "El tráfico del deseo: interseccionalidades no marco do turismo sexual no Nordeste do Brasil”, Quaderns-e, 4, disponível em < http://www.antropologia. cat/antiga/quaderns-e/04/04_03.htm > (última consulta em junho de 2019). 
PISCITELLI, Adriana, 2004c, "Exotismo e autenticidade: relatos de viajantes à procura de sexo”, em M.C. Silva (org.), Outros Trópicos: Novos Destinos Turísticos, Novos Terrenos da Antropologia. Lisboa, Livros Horizonte, 101-123.

PISCITELLI, Adriana, 2008, "Interseccionalidades, categorias de articulação e experiências de migrantes brasileiras", Sociedade e Cultura, 11 (2): 263-274.

PISCITELLI, Adriana, 2009, “Tránsitos: circulación de brasileñas en el ámbito de la transnacionalización de los mercados sexual y matrimonial”, Horizontes Antropológicos, 15 (31): $101-136$.

PISCITELLI, Adriana, 2011, “¿Actuar la brasileñidad? Tránsitos a partir del mercado del sexo", Etnográfica, 15 (1): 5-29, disponível em < https://journals.openedition.org/etnogra fica/765 > (última consulta em junho de 2019).

PISCITELLI, Adriana, 2016, "Economias sexuais, amor e tráfico de pessoas: novas questões conceituais", Cadernos Pagu, 47: el6475.

RIBEIRO, Fernando B., e Octávio SACRAMENTO, 2006, "Sexo, amor e interesse entre gringos e garotas em Natal”, Cronos: Revista do Programa de Pós-Graduação em Ciências Sociais da UFRN, 7 (1): 161-172.

RIBEIRO, Manuela et al., 2007, Vidas na Raia: Prostituição Feminina em Regiões de Fronteira. Porto, Afrontamento.

RIVERS-MOORE, Megan, 2012, "Almighty gringos: masculinity and value in sex tourism", Sexualities, 15 (7): 850-870.

ROCA GIRONA, Jordi, 2007, "Migrantes por amor: la búsqueda y formación de parejas transnacionales", AIBR: Revista de Antropología Iberoamericana, 2 (3): 430-458.

ROCA GIRONA, Jordi, 2011 , "[Re]buscando el amor: motivos y razones de las uniones mixtas de hombres españoles con mujeres extranjeras", Revista de Dialectología y Tradiciones Populares, LXVI (2): 487-514.

SACRAMENTO, Octávio, 2014, Atlântico Passional: Mobilidades e Configurações Transnacionais de Intimidade Euro-Brasileiras. Lisboa, ISCTE-IUL, tese de doutoramento.

SACRAMENTO, Octávio, 2016a, "Turismo e transnacionalização da intimidade nos trópicos globais”, Revista Turismo em Análise, 27 (2): 256-273.

SACRAMENTO, Octávio, 2016b, "Conjugalidades distendidas: trânsitos, projetos e casais transatlânticos”, DADOS: Revista de Ciências Sociais, 59 (4): 1207-1240.

SACRAMENTO, Octávio, 2018, "From Europe with passion: frameworks of the touristic male desire of Ponta Negra, in the North-East of Brazil", Current Issues in Tourism, 21 (2): 210-224.

SILVA, Manuel C., 2003, "Honra-vergonha: código cultural mediterrânico ou forma de controlo de mulheres?”, em José Portela e João Caldas (orgs.), Portugal Chão. Oeiras, Celta, 67-86.

SIMONI, Valerio, 2013, "Intimate stereotypes: the vicissitudes of being caliente in touristic Cuba”, Civilisations, 62: 181-198, disponível em < http://journals.openedition.org/civili sations/3320 > (última consulta em junho de 2019).

SIMONI, Valerio, 2014, "Coping with ambiguous relationships: sex, tourism, and transformation in Cuba", Journal of Tourism and Cultural Change, 12 (2): 166-183.

SIMONI, Valerio, 2015, Tourism and Informal Encounters in Cuba. Nova Iorque e Oxford, Berghahn Books.

SIMONI, Valerio, 2016, "Shaping money and relationships in touristic Cuba", em Gunnar Jóhannesson, Carina Ren e René van der Duim (orgs.), Tourism Encounters and Controversies: Ontological Politics of Tourism Development. Londres e Nova Iorque, Routledge, 21 -38. 
STOLCKE, Verena, 2006, "O enigma das interseções: classe, 'raça', sexo, sexualidade. A formação dos impérios transatlânticos do século XVI ao XIX”, Estudos Feministas, $14(1): 15-42$.

SUNDERLAND, Patricia, e Rita DENNY, 2016, "The social life of metaphors: have we become our computers", em Patricia Sunderland e Rita Denny (orgs.), Doing Anthropology in Consumer Research. Abingdon e Nova Iorque, Routledge, 93-1 10.

THURNELl-READ, Thomas, e Mark CASEY (orgs.), 2015, Men, Masculinities, Travel and Tourism. Basingstoke e Nova Iorque, Palgrave Macmillan.

TURNER, Victor, 1974, Dramas, Fields, and Metaphors: Symbolic Action in Human Society. Ithaca e Londres, Cornell University Press.

URRY, John, 1996, O Olhar do Turista: Lazer e Viagens nas Sociedades Contemporâneas. São Paulo, Studio Nobel.

WILliAmS, Erica, 2013, Sex Tourism in Bahia: Ambiguous Entanglements. Champaign, University of Illinois Press.

ZELIZER, Viviana, 2005, The Purchase of Intimacy. Princeton, Princeton University Press.

Receção da versão original / Original version

$2017 / 04 / 14$

Aceitação / Accepted

$2018 / 03 / 08$ 